\title{
A Psychological Study of the Inverse Relationship Between Perceived Risk and Perceived Benefit
}

\author{
Ali Siddiq Alhakami ${ }^{1}$ and Paul Slovic ${ }^{2}$
}

Abbreviated Title: Inverse Relationship

${ }^{1}$ Imam Muhammad Ibn Saud Islamic University Psychology Department. P.O. Box 15593, Riyadh, 11454 Saudi Arabia.

${ }^{2}$ Address correspondence to Paul Slovic at Decision Research, 1201 Oak Street, Eugene, Oregon 97401. 


\title{
A Psychological Study of the Inverse Relationship Between Perceived Risk and Perceived Benefit
}

\author{
Ali Siddiq Alhakami and Paul Slovic
}

\begin{abstract}
Judgments of risk and judgments of benefit have been found to be inversely related. Activities or technologies that are judged high in risk tend to be judged low in benefit and vice-versa. In the present study, we examine this inverse relationship in detail, using two different measures of relationship between risk and benefit. We find that the inverse relationship is robust and indicative of a confounding of risk and benefit in people's minds. This confounding is linked to a person's overall evaluation of an activity or technology. Theoretical and practical implications of this risk-benefit confounding are discussed.
\end{abstract}

In Press, Risk Analysis 
Judgments of risk and judgments of benefit have been found to be inversely related. Activities or technologies that are judged high in risk tend to be judged low in benefit and vice-versa. In the present study, we examine this inverse relationship in detail, using two different measures of relationship between risk and benefit. We find that the inverse relationship is robust and indicative of a confounding of risk and benefit in people's minds.

This confounding is linked to a person's overall evaluation of an activity or technology. Theoretical and practical implications of this risk-benefit confounding are discussed.

Key Words: perceived risk, perceived benefit. 


\section{INTRODUCTION}

\subsection{Background}

Analytic approaches to decision making treat risk and benefit as distinct concepts. The benefit one gains from driving to work is, presumably, qualitatively different from the risk. In some cases, such as with medical technologies, risks and benefits are not conceptually distinct or independent-the benefits are reductions in physical ailments and death. However, such cases of non-independence are relatively infrequent.

Studies in which people have been asked to judge risks and benefits have consistently observed an inverse (negative) correlation between perceived risk and perceived benefit across diverse hazards. The first such report, from the psychometric study by Fischhoff, Slovic, Lichtenstein, Read, and Combs ${ }^{(1)}$ found that, for 30 items examined, mean perceived risk and mean perceived benefit were inversely related; that is, the greater the perceived benefit, the lower the perceived risk and vice versa. For example, people tended to judge alcoholic beverages, handguns, and smoking as very low in benefit and very high in risk; on the other hand, they perceived prescription antibiotics, railroads, and vaccinations as having high benefit and relatively low risk.

Similar results were found by Slovic, Kraus, Lappe, and Major, ${ }^{(2)}$ who surveyed a representative sample of the adult population in Canada. Survey respondents were asked first to rate the riskiness of each of the 33 items; they then rated the benefit of each item. Both risk and benefit were rated on seven-point scales. A chart of the means of the perceived risk and benefit of the 33 hazards (Figure 1) clearly shows that perception of risk was inversely 
related to perception of benefit. The correlation between risk and benefit means was -.23 . Although-there-is variability in the-relationship;--in general one -sees that-the higher the perceived risk, the lower the perceived benefit, and vice versa.

Is the inverse relationship depicted in Figure 1merely a correct reflection of a fact about the world? Or might it reflect, at least in part, a confounding of risk and benefit in people's minds? The present study attempts to answer this second question.

Insert Figure 1about here

Evidence that risks and benefits are indeed confounded in the mind comes from new analyses that we performed on the data from Canada. Table I presents the correlations across 1261 survey respondents between perceived risk and perceived benefit for each of the 33 hazards studies in that survey. Negative correlations were present for 32 of the 33 hazard items and 30 of these 32 correlations were statistically significant. This means, for example, that persons who perceived nuclear power as high in risk tended to see it as low in benefit, and vice-versa. Why this inverse relationship is stronger for some hazards than for others is another question that the present study seeks to answer.

Insert Table I about here

Correlation has a limitation as a measure of the inverse relationship, however. For example, if everyone perceived an activity to be high in risk and low in benefit the correlation might well be zero despite the consistent discrepancy between the two kinds of 
perceptions. Therefore it seems necessary to us to calculate a second measure of the inverse relationship.- This measure is- the "-distance"- between perceived risk- and perceived benefit, defined as the absolute difference between the two judgments for a particular item. These absolute differences were calculated and then averaged across respondents for each item in the Canadian survey. ${ }^{(2)}$ The highest mean distance was obtained with cigarette smoking (D = $4.41)$, which was judged to be of low benefit $($ mean $=1.83)$ and high risk (mean $=6.00)$. High distance was also characteristic of alcohol $(\mathrm{D}=3.05)$, with a mean benefit of 2.56 and a mean risk of 5.02. Other items exhibiting high distance scores were those judged as high in benefit and low in risk, such as vaccines $(D=3.21$, mean benefit $=5.92$, and mean risk $=$ $2.93)$, insulin $(\mathrm{D}=3.13$, mean benefit $=6.07$, and mean risk $=3.21)$, and antibiotics $(\mathrm{D}$ $=2.88$, mean benefit $=5.98$, and mean risk $=3.46$ ).

A relatively small degree of distance between risk and benefit judgments was characteristic of menopause drugs, biotechnology drugs, heart surgery, antidepressants, laxatives, and cleansers. The small distance between perceived risk and perceived benefit suggests that individual respondents judged the risk and benefit at about the same level on the seven-point scale. The ordering of items based upon this distance measure is not significantly correlated with the ordering based upon the risk-benefit correlations shown in Table I. The rank-order correlation between the two measures of risk-benefit differences is -.04 .

If risks and benefits are confounded within people's minds, are there differences between persons in this regard? Again the answer is yes, based upon additional analyses of the Canadian survey data. The correlation between risk and benefit judgments was computed across the 33 hazard items for each of the 1261 respondents. Figure 2presents the distribution 
of these correlations. Negative correlations were characteristic of $83 \%$ of the respondents, -demonstrating the pervasiveness -of-this-pattern of-perception:-Although;-the-size of these correlations varied considerably across respondents more than one-quarter of the sample exhibited correlations more negative than -.41 . Tiemann and Tiemann, ${ }^{(3)}$ using a very different methodology, also observed a tendency of some persons, but not others, to judge risks as high and benefits low or vice-versa.

\section{Insert Figure 2 about here}

\subsection{Theoretical Issues}

The negative correlations found in previous studies suggest that people fail to consider the dimensions of risk and benefit separately. These negative correlations may be considered an interesting manifestation of the halo effect. The halo effect was first mentioned by Wells ${ }^{(4)}$ and later named by Thorndike. ${ }^{(5)}$ Halo occurs when individuals judge objects, people, or things in terms of general attitudes toward them. For example, when a person's overall impression of another individual is favorable, then his or her perceptions of that individual's attributes (such as intelligence, ability, physical appearance, etc.) tend to be favorable. Nisbett and Wilson ${ }^{(6)}$ manipulated people's positive attitude toward an instructor using videotaped interviews with the same individual. In one condition, the instructor was described as warm and friendly; in another condition, the instructor was described as cold and distant. The results indicated that persons who rated the "warm" instructor judged his 
appearance, mannerisms, and accent to be favorable; whereas those who rated the "cold" instructor found each of - these attributes to be unfavorable.

The psychological literature contains several theories that can explain the nonindependence among dimensions (halo effect). These fall into three broad categories: (a) theories that explain the halo effect as a result of the way concepts (including risks) are represented in the mind-cognitive consistency theories, for example; (b) theories that explain halo as a result of the influence of attitudes and affect on cognition; and (c) theories explaining halo as due to the way information is processed.

Cognitive consistency theories assert that people operate under a strong need for consistency among their beliefs. ${ }^{(7,8)}$ Thus, when people consider an activity or technology to be beneficial they may, to be consistent, also tend to view the technology has having low risk. The halo effect may also be caused by people's reliance on general evaluative attitudes or affective states when making risk/benefit judgments. ${ }^{(9)}$ When the attitude is favorable, the activity or technology being judged may be seen as having high benefit and low risk. On the other hand, when the item being evaluated is viewed unfavorably, with negative affect, it may be seen as having low benefit and high risk. Our general attitudes or affective states may thus "confound" the risk/benefit judgment. Information-processing theories ${ }^{(10)}$ imply that halo will be influenced by the familiarity with or knowledge of the technology and the concreteness or specificity of the dimensions people rate. Greater familiarity with what is being rated and greater specificity lead to less halo. The halo effect may also be a function of the salience or the availability of instances about risks and benefits. ${ }^{(1)}$ That is, when the 
benefit dimension is salient, it may inhibit the recall of instances of risk, and vice-versa, leading -to -an inverse relationship-and large-disparity between-risk and benefit-judgments.

\section{OBJECTIVES AND METHODS OF THE PRESENT STUDY}

As noted earlier, new analyses of the data from the Canadian survey by Slovic et al..$^{(2)}$ found negative correlations between perceived risk and perceived benefit across respondents for 32 of 33 items studied. These ranged between -.33 and -.03 . In the present study we investigate whether such negative relationships will replicate in another set of items based on hazardous activities and technologies. In addition, we attempt to identify the factors that determine the interdependence between risk and benefit judgments and to understand why some items have higher negative relationship than others. We shall also supplement correlational measures of relationship with measures of distance, defined above as the absolute value between scaled judgments of risk and benefit. High distance indicates that people view the item has having high benefit and low risk or vice versa.

\subsection{Methods}

Participants in this study were 100 students from the University of Oregon who participated to fulfill the requirements for an introductory psychology class.

Each participant evaluated 40 different items (activities and technologies) with regard to their perceived benefits and perceived risks. These items were drawn from previous riskperception research ${ }^{(12)}$ and were selected to encompass a wide range of hazard types. Risk was judged first, for all 40 items, followed by benefit judgments. 
Risk was defined in terms of the overall risk to U.S. society. Specifically, the following-question-was-asked:-"'In-general; -how risky do you consider-each of the following items to be for the United States society as a whole?" The scale ranged from (1) "not at all risky" to (7) "very risky."

Respondents were asked to answer the following question about benefits: "In general, how beneficial do you consider each of the following items to be for the United States society as a whole?" The scale ranged from (1) "not at all beneficial" to (7) "very beneficial."

After making their risk/benefit judgments, one half of the respondents were presented with a second questionnaire that included 20 of the 40 hazard items. The other respondents received the remaining 20 items. This split-half method was used because of the length of this second task. Each item appeared on a separate page. Respondents were asked to judge each item against the set of 25 bipolar scales, shown in Table II. In the test booklet, the item name (e.g., Nuclear Power, Pesticides, etc.) appeared at the top of the page of rating scales. The scales were selected to represent each of the three factors found by Osgood et al. ${ }^{(9)}$ to determine the affective meaning of objects. Specifically, these were the evaluation factor, which is defined by scales such as good-bad, or pleasant-unpleasant; the potency factor, which is defined by scales such as large-small or strong-weak; and the activity factor (e.g., active-passive, fast-slow). Several other scales were included to represent characteristics that have been found important in determining perception and acceptance of risks (e.g., knownunknown, familiar-unfamiliar, old-new, dread-not dread, voluntary-compulsory, fatal-not 
fatal, and controllable-uncontrollable). Respondents received the following instructions (adapted from Osgood et al: $\left.{ }^{(9)}\right)$ :

The second part of this experiment measures the meanings of different items (technologies and activities) to you by asking you to judge them against a series of descriptive scales. In performing this task, please make your judgments on the basis of what these technologies and activities mean to you. On each page of this booklet you will find an item to be judged and beneath it a set of scales. You are to rate the item on each of these scales in order.

Insert Table II about here

\subsection{Analysis}

1. Two measures of the risk/benefit relationship were calculated, one based upon correlations, the other on distances: (a) correlations between risk and benefit judgments were computed across respondents for each activity and technology; and (b) The distance between risk and benefit judgments was computed for each respondent by taking the absolute difference between the two judgments. These absolute differences were then averaged across respondents for each item.

2. The mean of each of the 25 bipolar scales was calculated for each item.

3. Factor analysis was performed on the intercorrelations among the means of the 25 bipolar scales to determine the factors that contributed significant variance to the judgments on these scales. 
4. Regression analyses were performed to determine the factors that affect the - magnitude and the direction of the correlation between -risk-and-benefit judgments and to determine the factors that affect the distance between risk and benefit judgments.

\section{RESULTS}

\subsection{Correlations and Distance Measures}

Table III presents the correlations across respondents between perceived risk and perceived benefit for each of the 40 items used in this study. Negative correlations were obtained for 38 items. Twenty-six correlations were significant at the .01 level. The highest negative correlations were -.52 for water fluoridation, -.51 for herbicides, and -.50 for DDT. Items that had low negative correlations included surgery, policy work, home appliances, fire fighting, prescription drugs, lasers, radiation therapy, air travel, bicycles, railroads, display screens, and so on.

Insert Table III about here

Table IV presents the mean ratings (across respondents) of perceived risk and benefit for each of the 40 items as well as the distance between risk and benefit measured by the mean absolute difference between risk and benefit judgments. The table indicates that the highest distance (5.24) was obtained with smoking, which was perceived as being of low benefit (1.27) and high risk (6.49). Asbestos and DDT were also judged as being of low benefit (2.05 and 2.54, respectively) and high risk (5.76 and 5.56). In contrast, solar power, 
vaccinations, bicycles, hydroelectric power, and computer displays were seen as having high benefit and-low risk: The -bottom of Table IV-shows-the items that had the-smallest

differences between risk and benefit judgments. Those items included food preservatives, radiation therapy, chemical fertilizer, nuclear power, and electric power (produced from coal).

Insert Table IV about here

Figure 3 presents a scatterplot of perceived benefit and perceived risk means for the 40 items. The plot shows that there is a curvilinear relationship between risk and benefit means (nonlinear $\mathrm{R}^{2}=.62 ; \mathrm{R}^{2}$ for the linear relationship is .49 ). The increment in $\mathrm{R}^{2}$ gained by including the nonlinear trend is significant $\left(\mathrm{F}_{1,37}=12.66 ; \mathrm{p}<.01\right)$. Perceived risk and benefit were almost unrelated when the risk level was perceived to be low or moderate. When the risk level increased, perceived benefit dropped sharply. This indicates that activities and technologies whose risks were judged to be low or moderate were perceived to be highly beneficial. When people perceived that the activity or technology had high risks, they judged its benefits as low.

Insert Figure 3 about here

How comparable are the two measures of the interdependency between risk and benefit judgments (i.e., distance and risk/benefit correlation)? Table V presents the 40 items along with their corresponding distances and risk/benefit correlations as well as the ranking 
of each item on these two variables. As the table indicates, although smoking ranked first with respect to-distance, it-ranked-24th - with-respect-to-risk/benefit correlation.--Similarly, solar power and bicycles were associated with high distances (4.50 and 3.85, respectively). and low negative correlations ( -.21 and -.12 , respectively). Appliances, on the other hand, were associated with low correlation (.02) but relatively high distance (3.13). Surgery had a low correlation (.06) and a medium distance of 2.43 .

\section{Insert Table $\mathrm{V}$ about here}

The correlation between distance and risk/benefit correlation was $-.15(\mathrm{p}=.30)$. This nonsignificant correlation highlights the discrepancies that exist between the two measures. To understand these discrepancies, we performed further analyses on some of the items that showed the most discrepancy. We found that in some cases where the distance between the mean risk and benefit judgment was high and the correlation was weak (e.g., home appliances), either the risk judgment or the benefit judgment had little variance, thus reducing the correlation. Discrepancies associated with large negative risk/benefit correlations but small distances (water fluoridation, herbicides, and nuclear power) tended to have risk and benefit ratings towards the middle of the scale, reducing the distance measure but allowing the inverse correlation to emerge. In sum, these analyses showed that the two measures of inverse interdependency were sensitive to the means and the variances of the risk/benefit judgments. 
These analyses indicate that neither correlation nor distance is an ideal measure of the inverse -interdependency between-risk and benefit judgments. Nevertheless, both-measures can be used to demonstrate this interdependency.

The previous analysis showed that the interdependency seemed to be evident across most technologies or activities. Such interdependency, however, is expressed differently with different measures. That is, the interdependency was observed in the form of strong negative correlations for some items (e.g., water fluoridation, herbicides, nuclear power, and chemical fertilizers), while for others it was evident from the high distance between risk and benefit judgments (e.g., smoking, solar power, bicycles, computer display screens, and home appliances). A few items, however, showed a low interdependency between risk and benefit judgments in that they were associated with weak negative correlations as well as low distances. These items included police work, radiation therapy, and food preservatives.

\subsection{Factor Analysis}

Principal-component analysis was performed on the intercorrelations among the 25 bipolar scales to discover which scales form coherent subgroups that are relatively independent of each other. Three factors with eigenvalues greater than 2 were retained. These three factors accounted for $81 \%$ of the total variance in the measures. After varimax rotation, the loadings of most of the variables on their corresponding factors were high and the variables grouped together in a way predicted by prior research. Factor 1 accounted for $52 \%$ of the total variance. It was most strongly defined by the following adjectives: fatal, severe, dangerous, harmful, dread, and violent on one pole and by good, fair, and nice on 
the other pole. This factor represents a blend of risk and evaluation. High scores were indicative of high-risk activities and technologies that tend to be evaluated unfavorably.

The second factor, which accounted for $17 \%$ of the total variance, was defined by the following scales: familiar-unfamiliar, known-unknown, voluntary-compulsory, and old-new.

The second factor thus represents a familiarity factor. High scores on this factor indicate high familiarity with and knowledge of the item. The third factor accounted for $12 \%$ of the variance. It consisted of the following scales: powerful-powerless, strong-weak, and activeinactive. This factor thus represents a potency factor.

\subsection{Prediction of Risk/Benefit Correlations}

We next examined whether the factors obtained from the principal components analysis presented above would predict the correlations between risk and benefit judgments.

On the basis of the theoretical considerations and prior research discussed earlier, we formulated the following hypotheses:

1. There would be a curvilinear (inverted U-shaped) relationship between respondents' evaluations of an item (measured by the item's score on the evaluative factor) and risk/benefit correlations. Specifically, we expected that items toward which people have either a strong positive or negative evaluation (close to one end or the other on Factor 1) would be associated with stronger negative correlations. On the other hand, items toward which people have no extreme evaluations would have weaker negative correlations. 
2. There would be a positive correlation between familiarity with the item (as measured by Factor -2) and risk/benefit-correlations: That -is,-the-greater the familiarity with the item, the weaker the negative correlation.

The third factor extracted from the principal component analysis (potency) was also included in the analysis to determine whether or not it related to the correlation between risk and benefit. No prediction was made regarding this factor.

To test these hypotheses, we contrasted two models: one included only the linear trend of the evaluative factor. The second model also included the quadratic trend, which was represented by the square of the evaluative factor. ${ }^{(13)}$ The familiarity factor and the potency factor were entered in both models only as linear variables. The two models were as follows:

$$
\begin{array}{ll}
\text { Model 1: } & y=A_{a}+b_{1} x_{1}+b_{2} x_{2}+b_{3} x_{3} \\
\text { Model 2: } & y=A_{a}+b_{1} x_{1}+b_{2} x_{1}^{2}+b_{3} x_{2}++b_{4} x_{3},
\end{array}
$$

where $y$ represents the risk/benefit correlation for an item, $x_{1}$ represents the evaluative factor score for that item, $\mathrm{x}_{1}^{2}$ represents the square of the evaluative factor, $\mathrm{x}_{2}$ represents the familiarity factor, and $x_{3}$ represents the potency factor.

A standard regression analysis, conducted to test the first model, yielded a significant $\mathrm{R}^{2}$ of $.23\left(\mathrm{~F}_{3,36}=3.61 ; \mathrm{p}<.05\right)$. The evaluative factor was the only significant predictor $(\mathrm{t}=2.41, \mathrm{p}<.05, \mathrm{~b}=.05)$. This indicates that more positive evaluations were associated with the higher (less negative) correlations between perceived risk and benefit. On the other hand, strong negative correlations between risk and benefit were associated with items that were evaluated negatively. The $\mathrm{R}^{2}$ obtained from the second model in which the quadratic 
trend was included was also .23 . No increment in $R^{2}$ was obtained. Thus, the specific test for the quadratic-trend (Model 2)-proved-not to be significant.

In the above analysis we used the evaluative factor as one predictor of the risk/benefit correlation. The evaluative factor, as we discussed earlier, contains a blend of risk scales (e.g., fatal-nonfatal, dread-not dread, and harmful-harmless) as well as evaluation scales (e.g., good-bad, pleasant-unpleasant, fair-unfair). In a subsequent analysis, however, we used the good-bad scale alone as a measure on the respondents' evaluative attitude toward the item (we shall refer the good-bad scale as Affect in the subsequent analysis). The good-bad scale ranges from 1 (good) to 7 (bad). Again, we predicted a curvilinear relationship between attitude and risk/benefit correlations. Thus, items associated with strong affect (whether positive or negative) were predicted to have strong negative correlations.

As before, two separate models were examined. The first included only the linear trend of affect, while the second one also included the quadratic trend. The results of the first (linear) model yielded a significant $\mathrm{R}^{2}$ of $.27\left(\mathrm{~F}_{3,36}=4.42 ; \mathrm{p}<.01\right)$. The nonlinear model produced an $R^{2}$ of .31 . This increase in $R^{2}$, however, was not significant. In both models, affect was the only significant predictor of risk/benefit correlations. Items that were judged as good were associated with less negative correlations; negative attitudes towards an item were associated with stronger negative correlations. This can be attributed to the fact that items with higher (i.e., smaller negative) correlations had the smallest betweenrespondent variance on benefit perception. The correlation between variance in benefit perception and risk/benefit correlations was $-.45(\mathrm{p}<.01)$, indicating that smaller negative correlations were associated with low controversy about the benefits of the technology or the 
activity. For example, fire fighting, which was judged as good (mean 1.32) had very low variability in perceived benefit $(\sigma=62)$ and a very weak nonsignificant negative correlation $(\mathrm{r}=-.06)$. Similarly, surgery, which was considered good (mean $=1.50)$, was associated with very little variance in benefit $\left(\sigma^{2}=.74\right)$ and a nonsignificant correlation of .06 . On the other hand, items with strong negative correlation tended to be negatively evaluated and showed high variance on perceived benefits. For example, DDT, which was judged to be bad (mean $=5.66)$, was associated with high variance on perceived benefit $\left(\sigma^{2}=1.96\right)$ and very strong negative correlation $(\mathrm{r}=-.50)$. Variance on perceived risk, however, was not associated with risk/benefit correlations, probably because there was rarely any item with low variance on perceived risk.

\subsection{Prediction of the Distance Between Risk and Benefit Judgments}

As noted earlier, the 40 items varied with respect to distance between their risk and benefit judgments (see Table IV). Some items were associated with high distances (e.g., smoking, solar power, and vaccinations), indicating that benefit and risk judgments for these items were polarized, that is high benefit was associated with low risk or vice versa. Other items were associated with low distance, such as food preservatives, radiation therapy, and chemical fertilizers. The aim of the following analysis was to determine the variables that predict the distance between risk and benefit judgments.

As before, we compared the predictive power of two models: the first included only the linear trend of the evaluative factor, while the second included the quadratic trend (the 
square of the evaluative factor). Both models also included the familiarity factor and the potency factor as predictors.

Model 1 produced a significant $\mathrm{R}^{2}$ of $.19\left(\mathrm{~F}_{3,36}=2.86 ; \mathrm{p}<.05\right)$. Model 2, which included the quadratic as well as the linear trend, produced an $R^{2}$ of $.72\left(F_{4,35}=22.01\right.$; $\mathrm{p}<.001)$. The increment in $\mathrm{R}^{2}$ was highly significant $\left(\mathrm{F}_{4,35}=66.25 ; \mathrm{p}<.001\right)$. The nonlinear effect of evaluation on distance was highly significant $(t=8.02, p<.001$, $\mathrm{b}=.54)$. Figure 4 is a plot of distance by the evaluative factor. As the figure shows, the distance between risk and benefit judgments was high for items that were evaluated positively and for items that were evaluated negatively. As evaluation moved toward the middle of the scale, the distance became small. When people had a clear positive or negative evaluation of a technology or an activity, judgments of risk and benefits were more polarized.

Insert Figure 4 about here

Substituting the good-bad scale for the evaluative factor produced results very similar to those obtained with the evaluative factor. Contrary to our expectation, familiarity did not show any consistent relationship with either the correlational measure or the distance measure. 


\section{DISCUSSION}

\subsection{Overview of Key Findings}

The purpose of this study was to investigate in detail the inverse interdependence between risk and benefit judgments observed in previous studies. Interdependence between risk and benefit judgments was measured in terms of (a) correlations between perceived benefit and perceived risk, and (b) the distance between risk and benefit judgments. The results confirmed the existence of strong inverse interdependence between risk and benefit judgments; negative correlations were characteristic of 38 of the 40 items studied. These negative correlations indicated that the higher the perceived benefit, the lower the perceived risk, and vice versa. Furthermore, the distance measure also indicated an inverse relationship between risk and benefit judgments across most of the 40 items studied. The correlation and distance measures, however, were not themselves highly correlated. Some items showed strong negative correlation but relatively low distance; other items showed high distance but weak negative correlations. Further analysis indicated that both measures were affected by the means and variances in perception of risk and perception of benefit. Both measures appear to be needed to provide insight into the inverse relationship between risk and benefit judgments.

A person's general affective evaluation of the item was the major predictor of the risk/benefit correlation. Strong negative correlations were associated with unfavorable evaluations, whereas weak negative correlations were associated with favorable attitudes. The results also revealed a curvilinear U-shaped relationship between affective evaluation and 
distance. Items with intense positive or intense negative evaluations had the largest distance between risk and benefit judgments. Items toward which people had positive-attitudes were viewed as having high benefit and low risks, whereas items toward which people had negative attitudes were viewed as having low benefits and high risks. Items in the middle of the evaluation scale were associated with smaller distances.

These findings of this study are congruent with theories in social psychology that attempt to explain the effect of attitudes on judgment and cognition. For example, cognitive consistency theory ${ }^{(7,8)}$ suggests that people operate under a strong need for consistency among their beliefs and attitudes. When people view an activity or technology as good, pressure toward consistency would lead them to judge its benefits as high and its risks as low and vice-versa for activities seen as bad. The results are also consistent with a growing body of research demonstrating the importance of affective states in judgment and decision making. ${ }^{(14-17)}$

\subsection{Directions for Future Research}

Although the present research demonstrates more clearly than before the interdependence of perceived benefit and perceived risk, it also raises a number of new questions for study. There is an obvious need to test the various psychological explanations described in Section 1.2. The present study was not designed to do this. One natural direction for future research would be to investigate whether the interdependency between risk and benefit judgments would be present in the judgments or technical analyses of risk- 
assessment experts. Another direction would examine whether the inverse relationship would be as strong with judgments of personal risks and benefits-as-with-societal risks-and benefits. It may be easier for people to differentiate risk and benefit at the personal level.

An intriguing implication of the finding that risk and benefit are confounded in people's minds is that it might be possible to change perceptions of risk by changing perceptions of benefit and to change perceptions of benefit by changing perceptions of risk. Indeed, Alhakami ${ }^{(18)}$ presents preliminary data showing that providing information designed to increase the perceived benefits of various technologies led to a decrease in the perceived risks of those technologies. Similarly, providing information indicative of high risk led to a decrease in perceived benefit. In this regard, it is interesting that promoters of nuclear power have recently focused their efforts on increasing people's appreciation of the benefits of this technology, rather than attempting to argue that it is safe. ${ }^{(19)}$ Although an increased appreciation of the benefits of nuclear power might well produce a decrease in perceived risk, the magnitude of the risk-benefit interdependency observed by Alhakami ${ }^{(18)}$ suggests that benefit-induced changes in perceived nuclear risks are likely to be small.

\section{ACKNOWLEDGMENTS}

This paper is based on parts of the first author's doctoral dissertation from the University of Oregon. We wish to thank Robert Mauro, Shinobu Kitayama, John Orbell, Joseph St. Sauver, John McQuaid, and Lewis Goldberg for their advice during the conduct of the research and Leisha Mullican for technical assistance. Perparation of this manuscript was supported by a grant from the Alfred P. Sloan Foundation. 


\section{REFERENCES}

1. B. Fischhoff, P. Slovic,--S.-Lichtenstein, S.S.-Read, and B.-Combs, "'How Safe is-Safe Enough? A Psychometric Study of Attitudes Towards Technological Risks and Benefits," Policy Sciences 9, 127-152 (1978).

2. P. Slovic, N.N. Kraus, H. Lappe, and M. Major, "Risk Perception of Prescription Drugs: Report on a Survey in Canada," Canadian Journal of Public Health 82, S15-S20 (1991).

3. A.R. Tiemann and J.J. Tiemann, "Cognitive Maps of Risk and Benefit Perceptions," in C. Whipple and V. Covello (eds.), Risk Analysis in the Private Sector (New York, Plenum, 1985) pp. 451-468.

4. F.L. Wells, "A Statistical Study of Literary Merit," Archives of Psychology 7 (1907).

5. E.L.A. Thorndike, "Constant Error in Psychological Ratings," Journal of Applied Psychology 4, 25-59 (1920).

6. R. Nisbett and T.D. Wilson, "Telling More Than We Can Know: Verbal Reports on Mental Processes," Psychological Review 84, 231-259 (1977).

7. F. Heider, "Attitudes and Cognitive Organization," Journal of Psychology 21, 107-112 (1946).

8. W.J. McGuire, "Theory of the Structure of Human Thought," in R.P. Abelson, E. Aronson, W.J. McGuire, T.M. Newcomb, M.J. Rosenberg, and P.H. Tannenbaum (eds.), Theories of Cognitive Consistency (Chicago, Rand McNally, 1968), pp. 140-162.

9. C.E. Osgood, G.J. Suci, and P.H. Tannenbaum, The Measurement of Meaning. (Urbana, University of Illinois Press, 1957).

10. W.H. Cooper, "Ubiquitous Halo," Psychological Bulletin 90, 213-244 (1981). 
11. A. Tversky and D. Kahneman, "Availability: A Heuristic for Judging Frequency and Probability," Cognitive Psychology 5, 207-232 (1973).

12. P. Slovic, B. Fischhoff, and S. Lichtenstein, "Characterizing Perceived Risk," in R.W. Kates, C. Hohenemser, and J.X. Kasperson (eds.), Perilous Progress: Technology as Hazard (Boulder, Colorado, Westview, 1985), pp. 91-123.

13. J. Cohen and D.L. Cohen, Applied Multiple Regression: Correlation Analysis for the Behavioral Sciences (2nd ed., Hillsdale, New Jersey, Erlbaum, 1983).

14. A.M. Isen and N. Geva, "The Influence of Positive Affect on Acceptable Level of Risk: The Person With a Large Canoe Has a Large Worry, Organizational Behavior and Human Performance 39, 145-154 (1987).

15. A.M. Isen and R. Patrick, "The Effect of Positive Feelings on Risk Taking: When the Chips Are Down," Organizational Behavior and Human Performance 31, 194-202 (1983).

16. E. Johnson and A. Tversky, "Affect, Generalization and the Perception of Risk," Journal of Personality and Social Psychology 45, 20-31 (1983).

17. R.B. Zajonc, "Feeling and Thinking: Preferences Need No Inferences," American Psychologist 35, 151-175 (1980).

18. A.S. Alhakami, "A Psychological Study of the Inverse Relationship Between Perceived Risk and Perceived Benefit of Technological Hazards," (Unpublished doctoral dissertation, University of Oregon, Eugene, 1991).

19. A. Bisconti, "Public Attitudes About Nuclear Waste," Nuclear Plant Journal, p. 49ff (July-August, 1991). 
Table I. Correlations Between Perceived Risk and Perceived Benefit for 33 Items ( $\mathrm{N}=1,261$; Canadian study, Slovic et al., 1991)

\begin{tabular}{|c|c|}
\hline Item & Correlation \\
\hline Nuclear Power & $-.33^{*}$ \\
\hline Alcohol & $-.30^{*}$ \\
\hline IUDs & $-.27 *$ \\
\hline Non-Prescription Drugs & $-.24^{*}$ \\
\hline Herbal Medicines & $-.24 *$ \\
\hline Aspirin & $-.23^{*}$ \\
\hline Acupuncture & $-.23 *$ \\
\hline Food Additives & $-.23^{*}$ \\
\hline Pesticides & $-.23 *$ \\
\hline Birth Control Pills & $-.22 *$ \\
\hline Artificial Sweeteners & $-.22 *$ \\
\hline Sleeping Pills & $-.20 *$ \\
\hline Tranquilizers & $-.20^{*}$ \\
\hline Cigarette Smoking & $-.20^{*}$ \\
\hline Biotechnology Drugs & $-.20^{*}$ \\
\hline Cleansers & $-.18^{*}$ \\
\hline Antidepressants & $-.17^{*}$ \\
\hline Insulin & $-.15^{*}$ \\
\hline Laxative & $-.14 *$ \\
\hline Antihypertensives & $-.14 *$ \\
\hline Vaccines & $-.13 *$ \\
\hline Menopause Drugs & $-.12 *$ \\
\hline X-Rays & $-.12^{*}$ \\
\hline Vitamin Pills & $-.12 *$ \\
\hline Antiarthritics & $-.12^{*}$ \\
\hline Cancer Drugs & $-.11 *$ \\
\hline Antibiotics & $-.11^{*}$ \\
\hline Appendectomy & $-.10^{*}$ \\
\hline Airplane Travel & $-.10 *$ \\
\hline Prescription Drugs & $-.08 *$ \\
\hline AIDS Drugs & -.05 \\
\hline Automobiles & -.03 \\
\hline Heart Surgery & .02 \\
\hline
\end{tabular}

*Significant at .01 level. 
Table II. Rating Scales

\begin{tabular}{|c|c|c|c|c|c|c|c|c|}
\hline Good & 1 ; & $2 ;$ & $3:$ & 4 ; & $5:$ & 6 i & 7 & $\mathrm{Bad}$ \\
\hline Changing & 1 & 2 & 3 & $4:$ & 5 & 6 & 7 & Steady \\
\hline Known & 1 & 2 & 3 & 4 & 5 & 6 & 7 & Unknown \\
\hline Nice & $1:$ & 2 & 3 ; & 4 i & 5 i & 6 & 7 & Awful \\
\hline Strong & $1:$ & 2 & 3 & 4 & 5 & 6 i & 7 & Weak \\
\hline Coarse & $1:$ & 2 & 3 & 4 & 5 & 6 & 7 & Fine \\
\hline Dangerous & 1 ; & 2 ; & 3 & 4 ; & 5 & 6 & 7 & Safe \\
\hline Poisonous & 1 ; & 2 & 3 i & 4 & 5 & 6 ; & 7 & Not Poisonous \\
\hline Voluntary & 1 ; & 2 & 3 & 4 ; & 5 ; & 6 & 7 & Compulsory \\
\hline Familiar & $1 ;$ & 2 & 3 & $4:$ & 5 & 6 & 7 & Unfamiliar \\
\hline Acceptable & $1:$ & 2 & 3 ; & $4:$ & 5 & $6:$ & 7 & Unacceptable \\
\hline Controllable & $1:$ & 2 & 3 & $4 ;$ & 5 & 6 & 7 & Uncontrollable \\
\hline Useful & 1 & 2 & 3 & $4:$ & 5 & 6 & 7 & Useless \\
\hline Violent & $1:$ & 2 & 3 ; & $4:$ & 5 & 6. & 7 & Calm \\
\hline Old & 1 i & 2 & 3 & $4:$ & 5 & 6 & 7 & New \\
\hline Active & 1 ; & 2 & 3 & $4:$ & 5 & 6 & 7 & Inactive \\
\hline Harmful & $1:$ & 2 & 3 ; & $4:$ & 5 & 6 & 7 & Beneficial \\
\hline Severe & $1 ;$ & 2 & 3 & 4 & 5 & 6 & 7 & Lenient \\
\hline Pleasant & $1:$ & 2 & 3 & $4:$ & 5 & 6 & 7 & Unpleasant \\
\hline Powerful & 1 ; & 2 & 3 ; & $4:$ & 5 & 6 & 7 & Powerless \\
\hline Pleasurable & $1 ;$ & 2 & 3 & $4:$ & 5 & 6 & 7 & Painful \\
\hline Worthless & 1 & 2 & 3 : & $4:$ & 5 & 6 & 7 & Valuable \\
\hline Dread & $1 ;$ & 2 ; & $3 ;$ & $4:$ & 5 & $6:$ & 7 & Not Dread \\
\hline Fair & $1 ;$ & 2 & 3 i & $4:$ & $5:$ & $6:$ & 7 & Unfair \\
\hline Fatal & 1 ; & 2 & 3 : & $4:$ & $5:$ & $6:$ & 7 : & Not Fatal \\
\hline
\end{tabular}


Table III. Correlations Between Perceived Risk and Perceived Benefit for 40 Items Across Subjects $(\mathrm{N}=100)$

\begin{tabular}{|c|c|}
\hline Item & Correlation \\
\hline Water Fluoridation & $-.52 *$ \\
\hline Herbicides & $-.51 *$ \\
\hline DDT & $-.50 *$ \\
\hline Asbestos & $-.48^{*}$ \\
\hline Motorcycles & $-.47 *$ \\
\hline Hydroelectric Power & $-.46^{*}$ \\
\hline Vaccinations & $-.43 *$ \\
\hline Handguns & $-.41 *$ \\
\hline Nuclear Power & $-.40^{*}$ \\
\hline Chemical Fertilizers & $-.40 *$ \\
\hline Automobile Travel & $-.35^{*}$ \\
\hline Alcoholic Beverages & $-.34 *$ \\
\hline Chemical Manufacturing Plants & $-.32 *$ \\
\hline Chemical Disinfectants & $-.32 *$ \\
\hline Large Constructions & $-.31 *$ \\
\hline Liquid Natural Gas & $-.31 *$ \\
\hline Electric Power (derived from coal) & $-.30^{*}$ \\
\hline X Rays & $-.30 *$ \\
\hline Pesticides & $-.29 *$ \\
\hline Microwave Ovens & $-.29 *$ \\
\hline General Aviation & $-.28 *$ \\
\hline Biotechnology & $-.25^{*}$ \\
\hline Prescription Drugs & $-.25 *$ \\
\hline Smoking & $-.22 *$ \\
\hline Commercial Aviation & $-.21 *$ \\
\hline Solar Power & $-.21 *$ \\
\hline Food Preservatives & -.16 \\
\hline Motor Vehicles & -.15 \\
\hline Computer Display Screens & -.14 \\
\hline Railroads & -.13 \\
\hline Anesthetics & -.13 \\
\hline Bicycles & -.12 \\
\hline Air Travel & -.12 \\
\hline Radiation Therapy & -.11 \\
\hline Lasers & -.09 \\
\hline Prescription Antibiotics & -.09 \\
\hline Fire Fighting & -.06 \\
\hline Home Appliances & -.02 \\
\hline Police Work & .05 \\
\hline Surgery & .06 \\
\hline
\end{tabular}

* Significant at .01 level. 
Table IV. Means of the Perceived Benefit, Perceived Risk and the Distance Between Perceived Benefit and Risk for the 40 Items Across Subjects $(\mathrm{N}=100)$

\begin{tabular}{|c|c|c|c|}
\hline Technology & Benefit & Risk & Distance \\
\hline Smoking & 1.27 & 6.49 & 5.24 \\
\hline Solar Power & 6.20 & 1.68 & 4.50 \\
\hline Vaccinations & 6.53 & 2.20 & 4.37 \\
\hline Asbestos & 2.05 & 5.76 & 3.93 \\
\hline Bicycles & 5.92 & 2.07 & 3.85 \\
\hline Hydroelectric Power & 5.83 & 2.52 & 3.43 \\
\hline Handguns & 2.81 & 5.60 & 3.33 \\
\hline Computer Display Screens & 5.25 & 1.97 & 3.30 \\
\hline DDT & 2.54 & 5.56 & 3.24 \\
\hline Home Appliances & 5.47 & 2.36 & 3.13 \\
\hline Alcoholic Beverages & 2.33 & 4.91 & 2.90 \\
\hline Motorcycles & 3.12 & 5.14 & 2.90 \\
\hline Prescription Antibiotics & 5.76 & 3.13 & 2.83 \\
\hline Railroads & 5.39 & 2.89 & 2.60 \\
\hline Microwave Ovens & 4.92 & 2.79 & 2.56 \\
\hline Air Travel & 5.96 & 3.68 & 2.48 \\
\hline Surgery & 6.31 & 3.96 & 2.43 \\
\hline Water Fluoridation & 4.42 & 2.87 & 2.39 \\
\hline Biotechnology & 5.28 & 3.24 & 2.36 \\
\hline Commercial Aviation & 5.54 & 3.50 & 2.34 \\
\hline Lasers & 5.36 & 3.43 & 2.27 \\
\hline Herbicides & 3.37 & 4.78 & 2.27 \\
\hline Fire Fighting & 6.49 & 4.38 & 2.26 \\
\hline Prescription Drugs & 5.67 & 3.77 & 2.26 \\
\hline Automobile Travel & 5.92 & 4.11 & 2.23 \\
\hline General Aviation & 5.42 & 3.44 & 2.22 \\
\hline Large Constructions & 4.92 & 3.08 & 2.18 \\
\hline Pesticides & 3.67 & 5.45 & 2.12 \\
\hline Anesthetics & 5.56 & 3.81 & 2.11 \\
\hline Nuclear Power & 4.58 & 5.48 & 2.02 \\
\hline X Rays & 5.66 & 4.19 & 1.99 \\
\hline Motor Vehicles & 5.74 & 4.37 & 1.99 \\
\hline Chemical Manufacturing Plants & 4.01 & 5.23 & 1.96 \\
\hline Electric Power (derived from coal) & 4.74 & 3.79 & 1.83 \\
\hline Chemical Disinfectants & 4.44 & 4.35 & 1.81 \\
\hline Chemical Fertilizers & 3.96 & 4.81 & 1.81 \\
\hline Natural Gas & 4.89 & 3.89 & 1.76 \\
\hline Police Work & 6.18 & 4.85 & 1.73 \\
\hline Food Preservatives & 4.01 & 4.05 & 1.50 \\
\hline Radiation Therapy & 4.80 & 5.17 & 1.47 \\
\hline
\end{tabular}

Note: Distance was computed for each subject by taking the absolute difference between risk and benefit judgments. These absolute differences were then averaged across subjects for each itẹm. 
Table V. Risk/Benefit Correlation, Distances and their Corresponding Ranks

\begin{tabular}{|c|c|c|c|c|}
\hline Item & Correlation & $\begin{array}{l}\text { Correlation } \\
\text { Rank }\end{array}$ & Distance & $\begin{array}{c}\text { Distance } \\
\text { Rank }\end{array}$ \\
\hline Water Fluoridation & $-.52 *$ & 1 & 2.39 & 18 \\
\hline Herbicides & $-.51 *$ & 2 & 2.27 & 22 \\
\hline DDT & $-.50 *$ & 3 & 3.24 & 9 \\
\hline Asbestos & $-.48 *$ & 4 & 3.93 & 4 \\
\hline Motorcycles & $-.47 *$ & 5 & 2.90 & 12 \\
\hline Hydroelectric Power & $-.46 *$ & 6 & 3.43 & 6 \\
\hline Vaccinations & $-.43 *$ & 7 & 4.37 & 3 \\
\hline Handguns & $-.41 *$ & 8 & 3.33 & 7 \\
\hline Nuclear Power & $-.40^{*}$ & 9 & 2.02 & 30 \\
\hline Chemicals Fertilizers & $-.40 *$ & 10 & 1.81 & 35 \\
\hline Automobile Travel & $-.35^{*}$ & 11 & 2.23 & 25 \\
\hline Alcoholic Beverages & $-.34 *$ & 12 & 2.90 & 11 \\
\hline Chemical Manufacturing Plants & $-.32 *$ & 13 & 1.96 & 33 \\
\hline Chemical Disinfectants & $-.32 *$ & 14 & 1.81 & 36 \\
\hline Large Constructions & $-.31 *$ & 15 & 2.18 & 27 \\
\hline Liquid Natural Gas & $-.31 *$ & 16 & 1.76 & 37 \\
\hline Electric Power (derived from coal) & $-.30 *$ & 17 & 1.83 & 34 \\
\hline X Rays & $-.30 *$ & 18 & 1.99 & 31 \\
\hline Pesticides & $-.29 *$ & 19 & 2.12 & 28 \\
\hline Microwave Ovens & $-.29 *$ & 20 & 2.56 & 15 \\
\hline General Aviation & $-.28 *$ & 21 & 2.22 & 26 \\
\hline Biotechnology & $-.25 *$ & 22 & 2.36 & 19 \\
\hline Prescription Drugs & $-.25^{*}$ & 23 & 2.26 & 24 \\
\hline Smoking & $-.22 *$ & 24 & 5.24 & 1 \\
\hline Commercial Aviation & $-.21^{*}$ & 25 & 2.34 & 20 \\
\hline Solar Power & $-.21 *$ & 26 & 4.50 & 2 \\
\hline Food Preservatives & -.16 & 27 & 1.50 & 39 \\
\hline Motor Vehicles & -.15 & 28 & 1.99 & 32 \\
\hline Computer Display Screens & -.14 & 29 & 3.30 & 8 \\
\hline Railroads & -.13 & 30 & 2.60 & 14 \\
\hline Anesthetics & -.13 & 31 & 2.11 & 29 \\
\hline Bicycles & -.12 & 32 & 3.85 & 5 \\
\hline Air Travel & -.12 & 33 & 2.48 & 16 \\
\hline Radiation Therapy & -.11 & 34 & 1.47 & 40 \\
\hline Lasers & -.09 & 35 & 2.27 & 21 \\
\hline Prescription Antibiotics & -.09 & 36 & 2.83 & 13 \\
\hline Fire Fighting & -.06 & 37 & 2.26 & 23 \\
\hline Home Appliances & -.02 & 38 & 3.13 & 10 \\
\hline Police Work & .05 & 39 & 1.73 & 38 \\
\hline Surgery & .06 & 40 & 2.43 & 17 \\
\hline
\end{tabular}

*Significant at .05 level. 


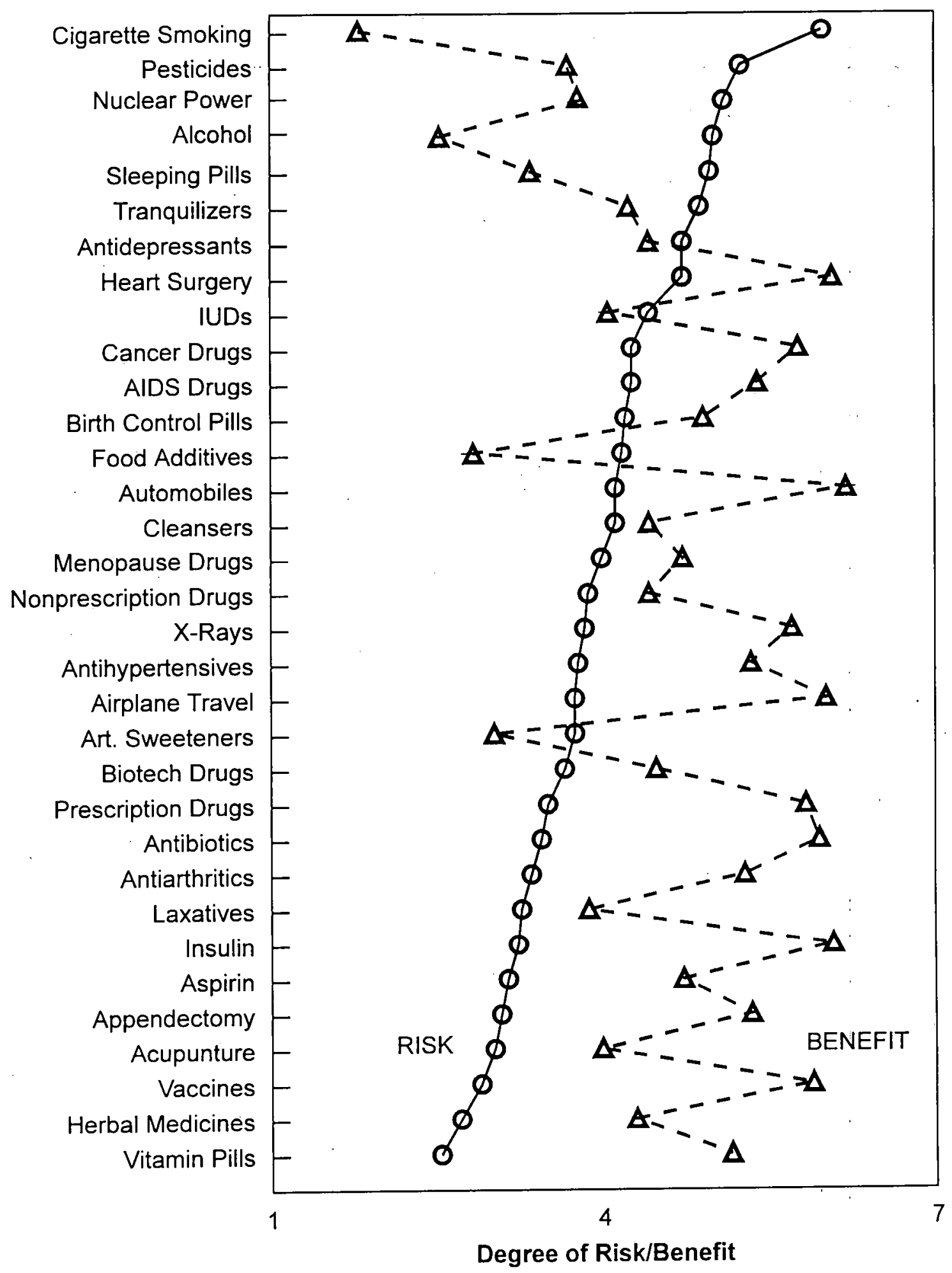

Figure 1. Means of the perceived risk and perceived benefit ratings in Slovic et al. (1991). 
Inverse Relationship

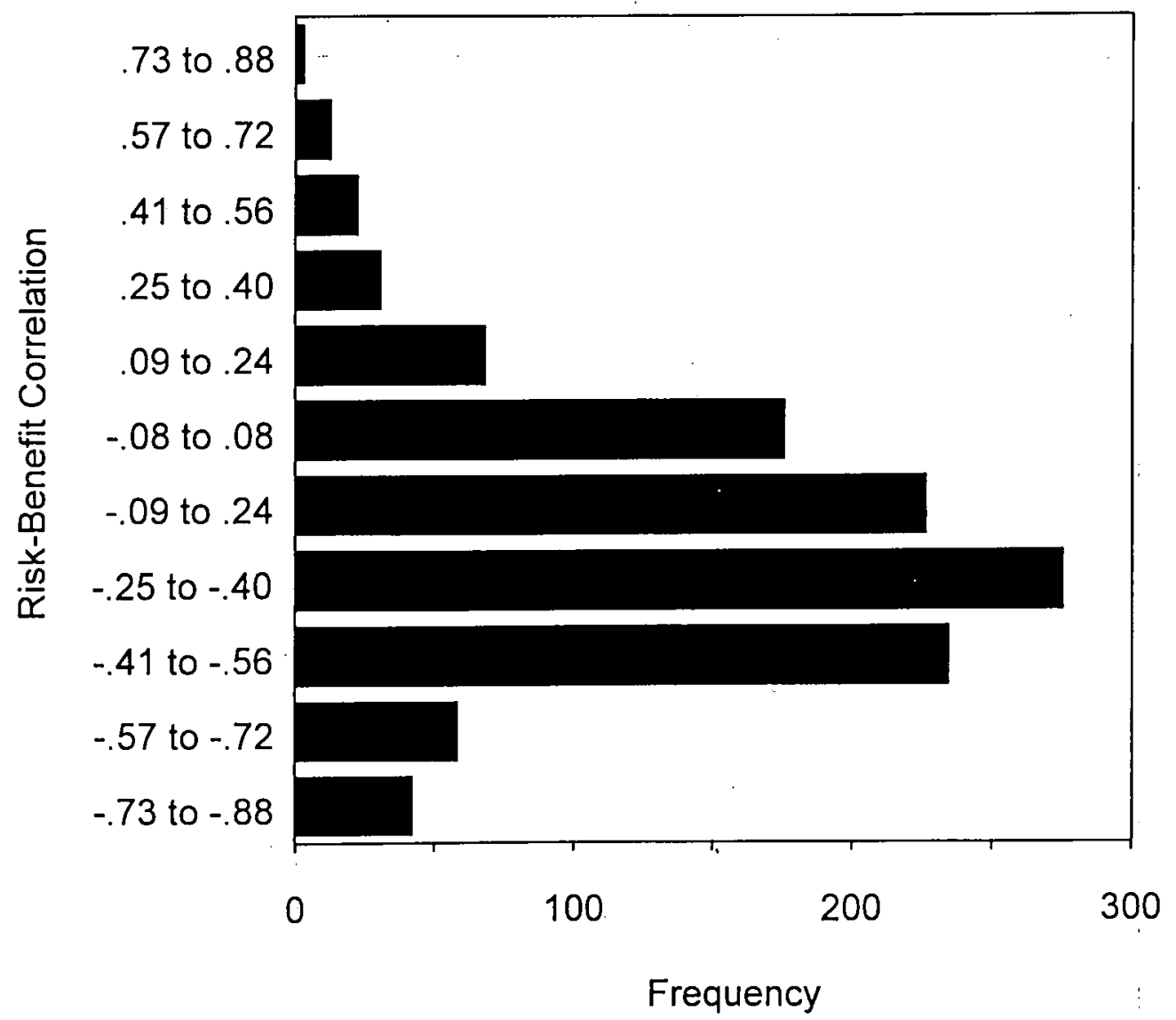

Figure 2. Frequency distribution of the risk-benefit correlation within each respondent and across hazards in Slovic et al. (1991). 


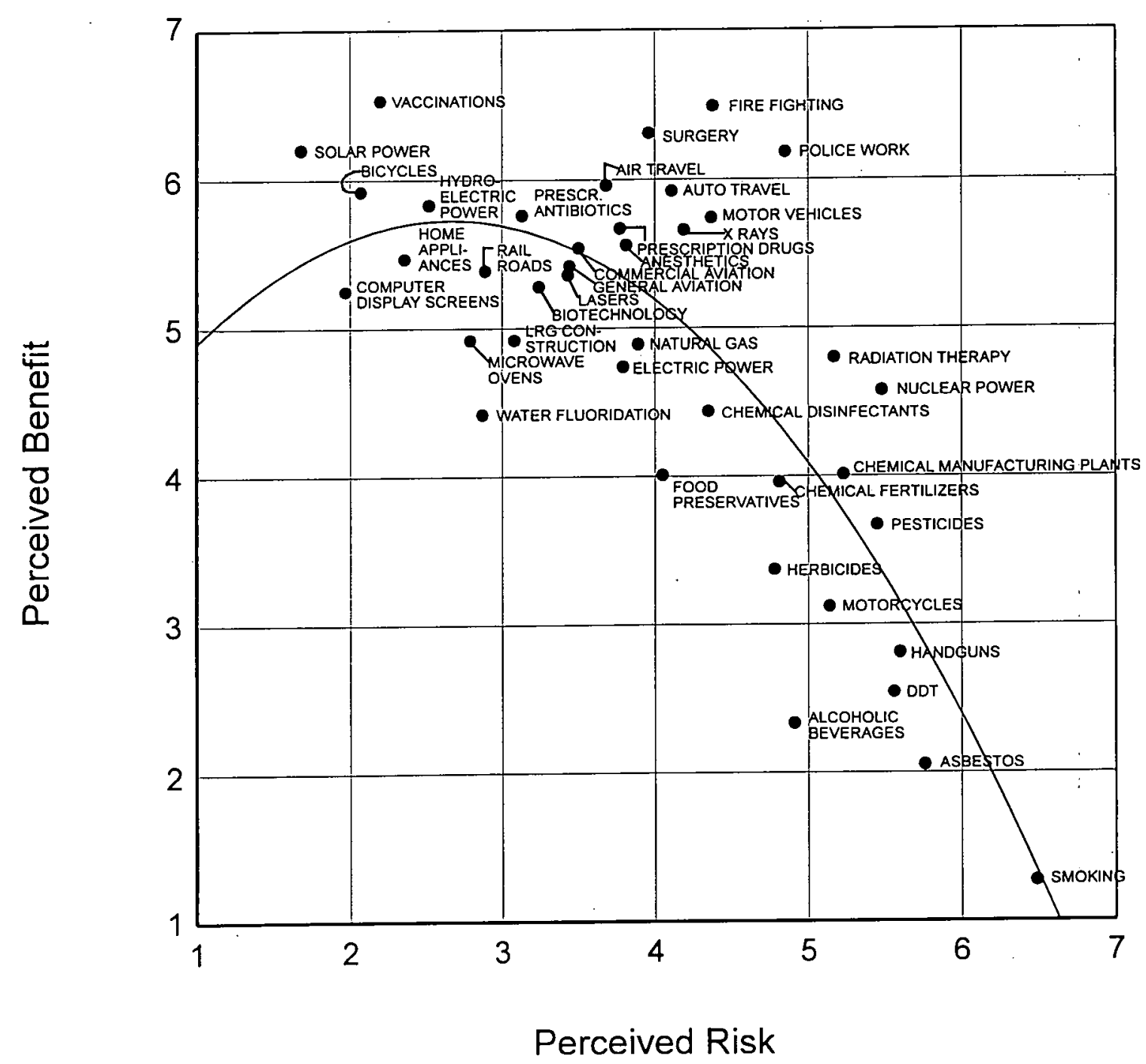

Figure 3. Scatterplot of risk/benefit means. 


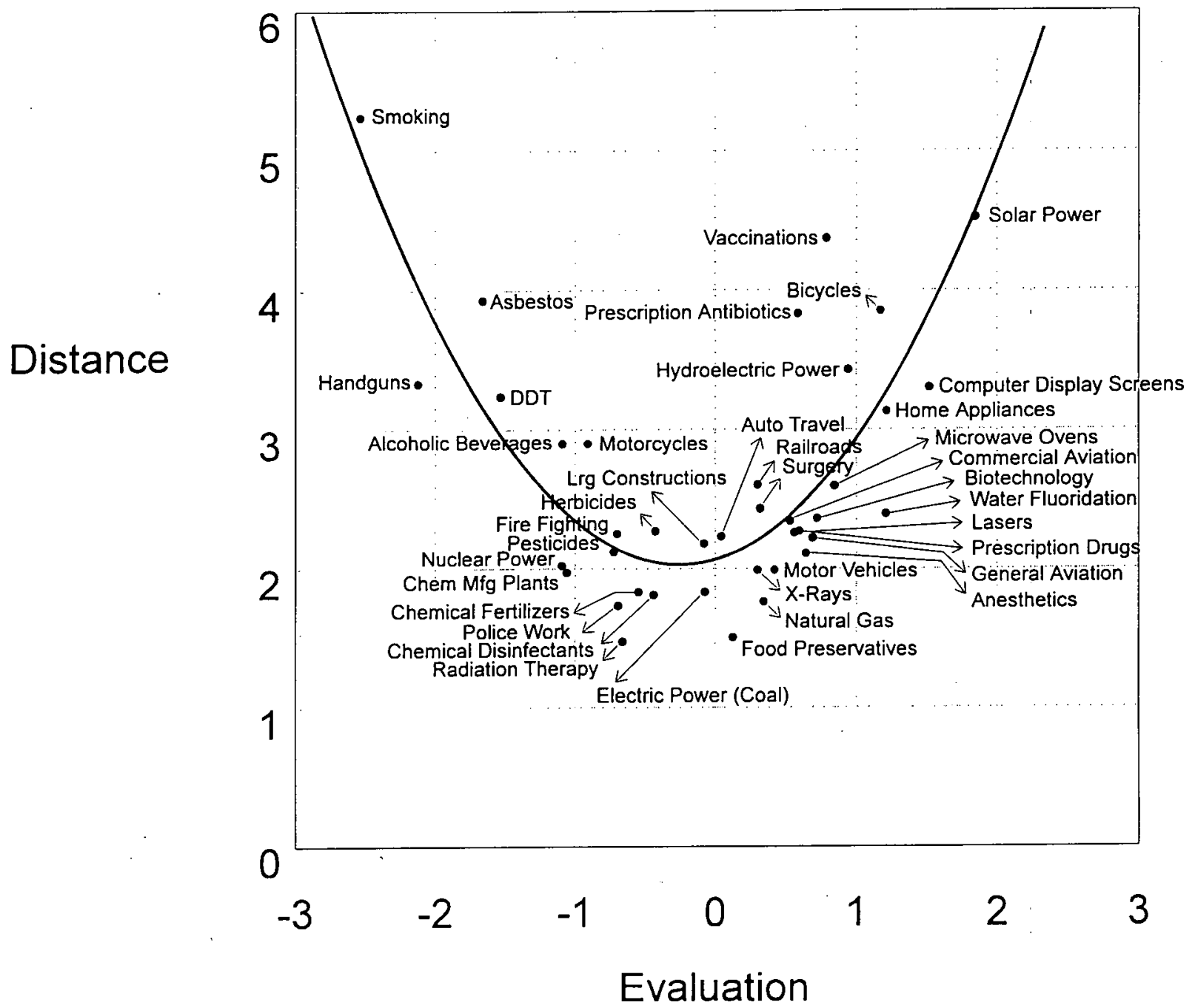

Figure 4. Scatterplot of distance by evaluation. 